\title{
Metastatic Neuroendocrine Carcinoma
}

National Cancer Institute

\section{Source}

National Cancer Institute. Metastatic Neuroendocrine Carcinoma. NCI Thesaurus. Code C155869.

A neuroendocrine carcinoma that has metastasized from its original site of growth to another anatomic site. 